\title{
A Política externa do Paraguai e a vigência atual de suas principais condicionantes históricas. Um balanço de Lugo a Cartes
}

\author{
Érica C. A. Winand ${ }^{l}$ \\ Luan Vieira Pimentel ${ }^{I I}$ \\ Joana Maria B. Andrade III \\ Jorge Matheus Oliveira Rodrigues ${ }^{I V}$
}

\begin{abstract}
Resumo: Historicamente, três foram os condicionamentos básicos da Política Exterior do Paraguai: Primeiramente, a forte presença dos Estados Unidos na América Sul, que terminava por limitar a autonomia de todos os países da região; Em seguida, a posição geopolítica paraguaia que impôs ao País forte submissão aos seus vizinhos, os quais, ao contrário do Paraguai, possuíam saída para o mar; e, por último, um traço peculiar doméstico referente à sua cultura política, profundamente assinalada por autoritarismo e golpismo. O objetivo do presente capítulo é explorar o Estado da Arte da Política Exterior do Paraguai, através dos fatos noticiados pelo Informe Paraguai de Política Externa - que compõe o Observatório de Política Exterior - , perguntando-nos em que medida as condicionantes históricas sintetizadas no primeiro parágrafo refletem o delineamento da política externa daquele Estado, na atualidade. Recortamos especificamente as relações com os Estados Unidos, o peso daquelas sobre as limitações da agenda paraguaia para com a América do Sul e para com parceiros essenciais, como o Brasil. Depois de traçar as condicionantes históricas que serão testadas quanto a sua permanência, buscaremos analisar conjunturalmente a política externa dos governos de Lugo a Cartes, no intuito de ressaltar continuidades e mudanças, bem como os fatores a elas associados.
\end{abstract}

Palavras-chave: Paraguai; Política Exterior; Estados Unidos; América do Sul.

\section{Paraguay's Foreign Policy and the current term of its main historical conditions.An analytical balance from Lugo to Cartes.}

\begin{abstract}
Historically, three were the basic determinants of Paraguay's Foreign Policy: First, the strong US presence in South America, which ended up limiting the autonomy of all countries in the region; Then the Paraguayan geopolitical position, landlocked with no access to the sea, contrary to its neighbors; and, finally, a domestic peculiar trait related to its political culture, deeply marked by authoritarianism and coups. The aim of this chapter is to explore the State of Art of the Paraguayan Foreign Policy through the facts reported in the Paraguay's Reports of Foreign Policy and Defense, reflecting how much the historical determinants summarized reflects the design of the foreign policy of Paraguay nowadays. We will focus especially in the relations with the United States and the weight of this country in the Paraguayan agenda with South America and with key partners, such as Brazil. After tracing the historical conditions, we will analyze conjuncturally the foreign policy of Lugo to
\end{abstract}


Cartes governments' in order to emphasize continuities and changes, as well as factors associated with them.

Keywords: Paraguay; Foreign Policy; U.S; South America.

Artigo recebido em 01/04/2016 e aprovado em 07/04/16.

\section{À guisa de introdução}

Historicamente, três foram os condicionamentos básicos da Política Exterior do Paraguai: Primeiramente, a forte presença dos Estados Unidos na América Sul, que terminava por limitar a autonomia de todos os países da região; Em seguida, a posição geopolítica paraguaia que impôs ao País forte submissão aos seus vizinhos, os quais, ao contrário do Paraguai, possuíam saída para o mar; e, por último, um traço peculiar doméstico referente à sua cultura política, profundamente assinalada por autoritarismo e golpismo. Sobre este último ponto, menos óbvio do que os dois primeiros, Espósito Neto destaca que durante décadas, a política externa paraguaia detinha-se ao objetivo de conservar os alicerces do Stronatto e para tanto: mantinha boas relações com os Estados Unidos com vistas a garantir recursos utilizados em prol da legitimação do regime político; buscava no Brasil apoio para diminuir a influência da Argentina em sua vida política, e, por último, procurava na Argentina o mesmo contrapeso em relação ao Brasil. ${ }^{\mathrm{V}}$

O objetivo do presente capítulo é explorar o Estado da Arte da Política Exterior do Paraguai, através dos fatos noticiados pelo Informe Paraguai de Política Externa ${ }^{\mathrm{VI}}$, perguntando-nos em que medida as condicionantes históricas sintetizadas no primeiro parágrafo refletem o delineamento da política externa daquele Estado, na atualidade. Recortamos especificamente as relações com os Estados Unidos, o peso daquelas sobre as limitações da agenda paraguaia para com a América do Sul e para com parceiros essenciais, como o Brasil. Depois de traçar as condicionantes históricas que serão testadas quanto a sua permanência, buscaremos analisar conjunturalmente a política externa dos governos de Lugo a Cartes, no intuito de ressaltar continuidades e mudanças, bem como os fatores a elas associados.

A presença dos Estados Unidos, as opções de política externa do Paraguai e suas relações com a América do Sul.

Enfraquecidas as teses sobre a iminência da falência dos Estados Unidos enquanto superpotência global e recapitulando-se a história da construção da hegemonia dos mesmos sobre a América Latina, jaz pertinente a reiteração de que a presença dos Estados Unidos 
constitui condicionante estrutural central da projeção da América do Sul, e das relações bilaterais entre os países que integram aquela porção regional.

A América do Sul, que desde a UNASUL ensaia com maior vigor a sua independência política, no que toca às escolhas dos métodos de concerto externo, ainda é alvo das iniciativas cerceadoras oriundas daqueles que constituem - ou assim se projetam - os maiores prejudicados com a autonomia dos mercados sul-americanos. Mesmo com a frustração da Área de Livre Acordo das Américas (ALCA), os Estados Unidos ainda ostentam forte presença na região, seja pelos inquebrantáveis laços comerciais com diversos Países, seja pela parceria estratégica que busca constantemente fortalecer, sobretudo, com os Estados menos assertivos em termos de Política Externa, e/ou mais fracos em termos de capacidade de manutenção da ordem interna. Por isso, segundo Samuel Pinheiro Guimarães, os estudos sobre a América do Sul passam necessariamente pela indagação primordial dos objetivos dos Estados Unidos para com a região. ${ }^{\mathrm{VII}}$. Apresentando como desígnio evidente a manutenção da hegemonia política, militar, econômica e cultural, os Estados Unidos lançam mão da estratégia de alinhamento com Países que adotem o mais amplamente possível, as medidas liberalizantes, que partem das estruturas comerciais e econômicas e chegam até a propriedade intelectual, por exemplo. Guimarães mostra que as últimas medidas naquele sentido, podem ser exemplificadas pelas recentes tratativas com o Chile, o Peru, a Colômbia e outros Países centro-americanos. ${ }^{\text {VIII }}$

O Brasil e a Argentina continuam sendo alvo de cobiça dos EUA, por encarnarem as duas maiores economias industriais da América do Sul. Entretanto, a partir da assunção dos governos Lula e Kirchner, respectivamente, ambos os Estados opuseram-se às medidas liberalizantes, propugnadas pela agenda extra-regional, priorizando o MERCOSUL e, posteriormente, a UNASUL. Embora o Brasil tenha flertado com a ALCA durante a Presidência de Fernando Henrique Cardoso, terminou recusando a continuidade das negociações já durante o primeiro mandato de Lula da Silva, sob a chancelaria de Celso Amorim, tendência seguida também pelas gestões do casal Kirchner, na Argentina. A própria Venezuela, que ergueu suas indústrias petroleiras, a partir de investimentos dos Estados Unidos, desde a década de 1920 e que, de modo relacionado, serviu, por décadas, tanto de mercado fornecedor de petróleo aos EUA, quanto de mercado consumidor de equipamentos para as tais indústrias, terminou, na gestão Chávez, rompendo com este vínculo, e aproximando-se também da América do Sul, o que ficou expresso no lançamento de sua candidatura ao MERCOSUL em 2001. A mesma fora aprovada entre os membros do bloco, com exceção do Paraguai. Como salienta Guimarães, a partir daquele momento "a recusa do Senado paraguaio em aprovar o ingresso da Venezuela no MERCOSUL tornou-se questão estratégica fundamental para a política norte-americana na América do Sul". IX A incorporação da Venezuela ao MERCOSUL, fato tão importante pelo peso estratégico que aquele País agrega ao fortalecimento do bloco em questão, só foi possível porque o Paraguai esteve suspenso do concerto por descumprir com a cláusula democrática. Caso contrário, possivelmente, teria feito valer sua oposição, sob incentivo dos Estados Unidos.

Acima exposto, encontra-se apenas um dos exemplos de como o Paraguai, dado às suas fragilidades pode constituir elemento de desagregador para a integração Sul-Americana, motivo pelo qual merece justa atenção dos formuladores regionais de política externa. E, por outro lado, de como suas fragilidades internas podem ser instrumentalizadas pelos Estados 
Unidos, afim de que o fortalecimento regional não ocasione a perda de sua influência sobre área de seu histórico domínio.

A relação do Paraguai com os Estados Unidos mereceria considerável retrospectiva histórica, mas para o fim que queremos atingir, basta lembrar que assim como a maioria dos Países latino-americanos, o Paraguai estabeleceu ditadura que obedecia aos princípios da Doutrina de Segurança Nacional (DSN), formulada pelos Estados Unidos durante a Guerra Fria. Entre os anos 1950 e 1960, recebeu grande monta de ajuda financeira dos EUA, em troca de um vigilante serviço de controle do comunismo. Não tardou, porém, para que os Estados Unidos passassem a controlar a vida interna do Paraguai, pressionando-o pela efetivação do combate às atividades ilícitas e oferecendo seus recursos, como forma de cooperação para alcance das metas que propunham. ${ }^{\mathrm{X}}$

Neste sentido, pode-se supor que o Paraguai teria sido mais pressionado pelos Estados Unidos do que outros países latino-americanos, pela particular fragilidade da ordem interna, ilustrada pela cultura golpista, assim como pelo alto índice de tráfico de drogas, lavagem de dinheiro, corrupção e prostituição infantil. A Ditadura de Stroessner foi a que gerou aos Estados Unidos maior conforto quanto ao categórico comprometimento de contenção ao comunismo. Segundo Kfuri e Lamas,

\footnotetext{
O apoio à potência capitalista não ficava apenas no campo da retórica, mas traduziase nas ações concretas da política externa paraguaia no período. Além de votar consistentemente com os Estados Unidos na Organização das Nações Unidas (ONU) e na Organização dos Estados Americanos (OEA), o Paraguai forneceu duas centenas de soldados para ajudar na intervenção norte-americana na República Dominicana e ofereceu tropas para lutar no Vietnã. ${ }^{\text {XI }}$
}

Todavia, tão particular como seu alinhamento à Guerra Fria, fora a opressão sofrida pelo Paraguai pelos mesmos Estados Unidos que financiaram a violência interna.

Assim como todos os Países latino-americanos que implantaram ditaduras financiadas pelos Estados Unidos, o Paraguai sofreu os revezes daquele apoio e aqui, mencionaremos alguns contextos específicos: Durante o governo Nixon, o Paraguai foi retaliado com subtração de ajuda econômica e imposição de barreira à entrada de seu açúcar nos Estados Unidos, devido à sua conexão com a França, no tráfico de heroína. Durante a gestão Carter, sob a égide da promoção dos Direitos Humanos, os Estados Unidos retiraram a ajuda financeira e arrefeceram as relações comerciais pelo fato de ser o Paraguai um Estado destacado pelo alto índice de violência, executada por parte de suas forças de segurança. No decorrer da era Reagan, a promoção da democracia, dos Direitos Humanos e de contenção da circulação de drogas, levou os Estados Unidos a recrudescer aquela pressão, ocasionando ao Paraguai sério isolamento diplomático. XII

$\mathrm{Na}$ década de 1980, conhecida como "década perdida", no concernente ao desenvolvimento da América Latina, não apenas a pressão advinda dos Estados Unidos, mas a cobrança de altíssimos juros por parte dos mesmos era algo comum ao continente. Todavia, como detalha Moniz Bandeira, ao final da década,: 
Essa crise, que começava a afetar seriamente os interesses dos Estados Unidos ao reduzir na América Latina a capacidade de importar e atender ao serviço da dívida externa levou o Institute for International Economics a promover uma conferência, para a qual foram convidados economistas de oito países latino-americanos Argentina, Brasil, Chile, México, Venezuela, Colômbia, Peru e Bolívia, com a finalidade de formular um diagnóstico e sugerir medidas de ajustamento para sua superação. XIII

As propostas de reforma elaboradas por diversos atores estadunidenses, conhecidas como "Consenso de Washington", grosso modo, concentraram-se na necessidade de liberalização e privatização como estratégias de estabilização monetária. Na América Latina, a cartilha do Consenso de Washington foi imposta como condição para renegociação da dívida para com os Estados Unidos, bem como para recebimento de auxílio de instituições internacionais como BID ou BIRD. (Moniz Bandeira, 2002, p.136). Conforme evidencia Bandeira, cada país da América do Sul sofreu distintas repercussões da nova imposição da década de 1990. Não obstante a todos fossem comuns consequências como: a crise financeira, o agravamento de déficits nas contas internas e externas e outras vicissitudes econômicas e políticas; algumas particularidades políticas e econômicas ocasionaram gradações nos efeitos das reformas. No Paraguai,

[...] a economia, estagnada desde o término da construção de Itaipu (1982), entrara em franca retração, a partir de 1996, o PIB caiu 0,6\%, em 1998, e 0,1\%, em 1999, e os problemas sociais agravaram-se. O aguçamento da exclusão social, a extrema pobreza, alcançando pelo menos um terço dos camponeses, o aumento do desemprego, saltando de 6\%, em 1995, para 15\%, em 1999, e a deterioração das condições de vida das classes médias tornavam cada vez mais possível uma convulsão social. E, em 5 de junho de 2002, quando cerca de 3.000 camponeses marcharam sobre Assunção, o presidente Luis González Macchi, submetido a processo e diante da ameaça de greve geral por trinta dias, cedeu e derrogou a lei 1.615, que autorizava a privatização da companhia telefônica Copasco, a empresa de água potável Essap e a ferroviária estatal. XIV

Desta feita, a particular precariedade econômica e política do Paraguai arrochava sua margem de manobra, fazendo-o ceder mais facilmente aos interesses dos Estados Unidos.

De um modo generalista, processos de integração da América do Sul surgiram como alternativa de fortalecimento frente às pressões advindas, sobretudo do Consenso de Washington. A soma de forças que já se processava durante a década perdida, através de ensaios de integração regional ganhou maior densidade nos momentos que precederam a criação do MERCOSUL. À título de revisão histórica, em 1980 criou-se a ALADI, por meio do Tratado de Montevidéu. Em 1985, Sarney e Alfonsin assinaram a Declaração de Iguaçu que fundara o Programa de Integração e Cooperação Econômica (PICE) que ensejou, por sua vez, a formação do arcabouço institucional do futuro MERCOSUL, finalmente estabelecido em 1991. Embora articulado como mecanismo de contrapeso ante pressões estrangeiras, durante sua fase de incubação no governo de Sarney, o projeto do MERCOSUL terminou sendo operacionalizado pelos governos seguintes, como os de Collor e Cardoso, como ponta de lance da liberalização econômica, sendo, portanto, arrastado pelo mainstream da década de 1990. Esta não teria sido condução particular do Brasil. Como analisa Briceño Ruiz, a década 
de 1990 foi marcada pela homogeneidade ideológica determinante da lógica integrativa adotada que, basicamente era instrumentalizada a serviço da inserção competitiva nos mercados econômicos mundiais. Aquele modelo recebeu da Comissão Econômica para América Latina e Caribe (CEPAL), o nome de "regionalismo aberto". (BRICEÑO RUIZ, 2013. In: CARMO, et al, 2013, p.196). Para Amado Cervo, aquela situação de confluência ideológica teria se dado menos por pressões externas do que como "uma invenção da inteligência política latino-americana da década de 1990" que, uma vez se estabelecido com tamanha força e coesão, alimentou o que o autor designou de "Paradigma do Estado normal". $\mathrm{XV}$

Embora, no âmbito privado, alguns logros, no sentido de maior abertura alfandegária, de modernização e ampliação da base produtiva latino-americana, dentre outros, tenham sido alcançados, o MERCOSUL terminou regido pelo embalo das idas e vindas negociais, decorrentes de interesses dissonantes e de assimetrias nacionais irresolutas dentro do bloco, o que, de acordo com Vigevani e Ramanzini Jr. foi agravado pela fraca presença estatal:

Não foram criados os instrumentos necessários para dar sustentabilidade à integração, isto é, instrumentos que permitissem ações públicas de desenvolvimento social e econômico, assim como a atenuação das grandes desigualdades entre os Estados e internamente a cada Estado. XVI

De modo geral, a abertura acrítica advinda do modelo neoliberal, culminou no acirramento de dependências estruturais que tornou vulnerável a inserção internacional dos Estados do bloco. XVII

O chamado "regionalismo aberto" passou a sofrer críticas no Brasil, a partir da crise do Real em 1998, e na Argentina, após a crise de 2001. No Brasil, houve tentativas, por parte da segunda gestão de Cardoso, de associação do modelo neoliberal ao parâmetro de desenvolvimento nacional, considerando-se o caráter assimétrico da globalização, o que se enquadraria ao paradigma do "Estado logístico", assim denominado por Cervo (2003, p.22), o qual, segundo o autor, não resultou em práticas efetivas. Todavia, foi a partir da tomada do poder por partidos de esquerda em países como Brasil, Argentina, Venezuela, Uruguai, Bolívia e Equador, que o regionalismo latino-americano deixa de ser caracterizado pelo consenso neoliberal, o que, contudo, não cedeu lugar a um consenso contra hegemônico, no que toca ao plano econômico, nem ao político.

É mister destacar que embora tenha aderido à onda neoliberal, o MERCOSUL nunca representou ao Paraguai altas possibilidades de inserção internacional, pela própria inexpressividade do seu poder de barganha. Como ressaltam Kfuri e Lamas (2006, pp.13-19), não se pode afirmar que houve no Paraguai claro movimento anti-MERCOSUL, assim como não devem passar despercebidas nem a resistência do Partido Colorado, tampouco a rejeição do empresariado que temiam que o bloco propiciasse maior dependência paraguaia em relação aos participantes mais expressivos, como era o caso do Brasil e da Argentina. No entanto, a adesão paraguaia ao MERCOSUL ocorreu sob o receio predominante de que sua não adesão poderia dificultar suas relações com a Organização Mundial do Comércio (OMC) e, particularmente, com os Estados Unidos. 
Até meados da década de 1990, houve um alinhamento quadripartite (Brasil, Argentina, Paraguai e Uruguai) para negociações com os Estados Unidos, que ficou conhecido como mecanismo 4+1. Mas na maior parte do tempo, o MERCOSUL realmente funcionou de modo paralelo ao bilateralismo das relações entre Brasil e Argentina, e sob o signo de flagrante assimetria que prejudicava, sobretudo, Paraguai e Uruguai. Assim, torna-se compreensível o fato de que os últimos passassem a buscar apoio externo para reduzir aquelas assimetrias, ainda que a busca pudesse encaminhar o bloco à iminência da fragmentação. Naquele contexto, o Paraguai assinou com os Estados Unidos mais de 17 Acordos em diferentes setores.

As relações entre ambos se intensificaram após os atentados de 11 de Setembro de 2001 nos Estados Unidos e depois da consequente reorientação da Política Externa dos últimos, retomando foco na segurança e na luta contra o terrorismo.

Antes daquele novo momento, o Paraguai já era alvo de monitoramento dos Estados Unidos, por abrigar atividades ilícitas, particularmente tráfico internacional de drogas. Se a ênfase da ação internacional dos Estados Unidos, no pós-Guerra Fria era a "guerra às drogas", o que absorveu parte majoritária das operações militares durante a década de 1990, após os ataques de 2001, a "guerra ao terror" substituiu a tônica. XVIII

A partir das prisões de integrantes da Hizbollah, da Organização Terrorista Al Gamáa al-Islammya e da Al-Qaeda, o Paraguai foi deliberadamente reconhecido pelos Estados Unidos como preocupante foco de atividade terrorista. ${ }^{X I X}$ A fixação do Paraguai como base estratégica passou a ser mais ostensivamente perseguida pelos Estados Unidos, o que fez com que entendimentos bilaterais se tornassem mais complexos, já que o Paraguai recebia contrapartidas econômicas e comerciais pelas facilidades que aos poucos foi abrindo aos acordos militares.

Entre os anos de 2001 a 2015, dos 36 Acordos firmados entre Paraguai e Estados Unidos, 17 abordaram cooperação para controle de narcóticos, 09 se relacionaram especificamente a assuntos militares e de cooperação em Defesa, 03 versaram sobre propriedade intelectual, 2 sobre corrução e impunidade, 1 sobre comércio e investimentos, 1 sobre meio-ambiente e 1 relativo à controle de abalos sísmicos. Isto mostra que a matéria dos Atos assinados entre os dois Países continuou priorizando as questões relacionadas à Típlice Fronteira. Ou seja, o Paraguai seguiu subordinado aos Estados Unidos nas questões de Segurança, com modo de obtenção de contrapartidas econômicas.

Acordos Bilaterais Paraguai - Estados Unidos (2001-2015):

\begin{tabular}{|l|l|l|l|l|l|}
\hline $\mathrm{N}^{\mathbf{0}}$ & Tratado & Tipo & Matéria & País & Data \\
\hline
\end{tabular}




\begin{tabular}{|c|c|c|c|c|c|}
\hline 1 & \begin{tabular}{lrr} 
ACUERDO & POR & NOTAS \\
REVERSALES & PARA & LA \\
PARTICIPACIÓN & & DE \\
EFECTIVOS DE LAS & FUERZAS \\
ARMADAS DE LOS & ESTADOS \\
UNIDOS EN & EL & EJERCICIO \\
CONJUNTO & \multicolumn{2}{c}{ "NUEVOS } \\
HORIZONTES" & ENTRE & EL \\
GOBIERNO DE LA REPÚBLICA \\
DEL PARAGUAY r Y & EL \\
GOBIERNO DE LOS ESTADOS \\
UNIDOS DE AMÉRICA
\end{tabular} & Bilateral & $\begin{array}{l}\text { Acordo de } \\
\text { Exercício e } \\
\text { Intercâmbi } \\
\text { o Militar }\end{array}$ & $\begin{array}{l}\text { Estados } \\
\text { Unidos }\end{array}$ & $30 / 01 / 2001$ \\
\hline 2 & $\begin{array}{lrr}\text { ACUERDO } & \text { POR } & \text { NOTAS } \\
\text { REVERSALES } & \text { PARA } & \text { LA } \\
\text { PARTICIPACIÓN } & \text { DE } \\
\text { EFECTIVOS DE LAS FUERZAS } \\
\text { ARMADAS DE LOS ESTADOS } \\
\text { UNIDOS EN LA OPERACIÓN } \\
\text { RIBERENA DEL EJERCICIO } \\
\text { UNITAS ENTRE EL GOBIERNO } \\
\text { DE LA REPÚBLICA DEL } \\
\text { PARAGUAY Y EL GOBIERNO } \\
\text { DE LOS ESTADOS UNIDOS DE } \\
\text { AMÉRICA }\end{array}$ & Bilateral & $\begin{array}{l}\text { Acordo de } \\
\text { Exercício e } \\
\text { Intercâmbi } \\
\text { o Militar }\end{array}$ & $\begin{array}{l}\text { Estados } \\
\text { Unidos }\end{array}$ & 06/07/2001 \\
\hline 3 & 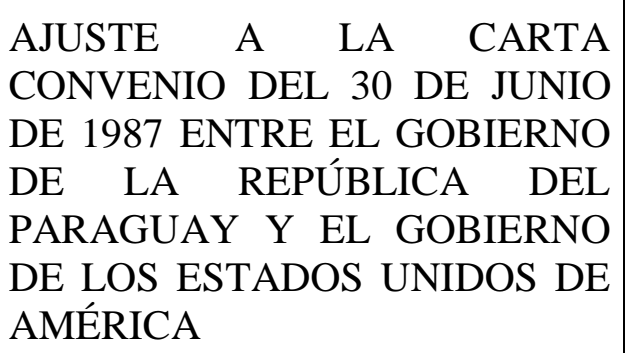 & Bilateral & $\begin{array}{l}\text { Emenda à } \\
\text { carta } \\
\text { convênio } \\
\text { sobre } \\
\text { controle de } \\
\text { narcóticos }\end{array}$ & $\begin{array}{l}\text { Estados } \\
\text { Unidos }\end{array}$ & $27 / 09 / 2001$ \\
\hline
\end{tabular}




\begin{tabular}{|c|c|c|c|c|c|}
\hline 4 & $\begin{array}{lrr}\text { ACUERDO POR } & \text { NOTAS } \\
\text { REVERSALES PARA } & \text { LA } \\
\text { PARTICIPACIÓN } & \text { DE } \\
\text { EFECTIVOS DE LAS FUERZAS } \\
\text { ARMADAS DE LOS ESTADOS } \\
\text { UNIODOS EN LA OPERACIÓN } \\
\text { RIBERENAA DEL EJERCICIO } \\
\text { UNITAS 2002 ENTRE EL } \\
\text { GOBIERNO DE LA REPÚBLICA } \\
\text { DEL PARAGUAY Y EL } \\
\text { GOBIERNO DE LOS ESTADOS } \\
\text { UNIDOS DE AMÉRICA }\end{array}$ & Bilateral & $\begin{array}{l}\text { Acordo de } \\
\text { Exercício e } \\
\text { Intercâmbi } \\
\text { o Militar }\end{array}$ & \begin{tabular}{|l} 
Estados \\
Unidos
\end{tabular} & $02 / 07 / 2002$ \\
\hline 5 & $\begin{array}{l}\text { CARTA DE ENTENDIMIENTO } \\
\text { ENTRE EL MINISTERIO DE } \\
\text { RELACIONES EXTERIORES DE } \\
\text { LA REPÚBLICA D DL } \\
\text { PARAGUAY Y LA EMBAJADA } \\
\text { DE LOS ESTADOS UNIDOS DE } \\
\text { AMÉRICA }\end{array}$ & Bilateral & $\begin{array}{l}\text { Emenda à } \\
\text { carta } \\
\text { convênio } \\
\text { sobre } \\
\text { controle de } \\
\text { narcóticos }\end{array}$ & $\begin{array}{l}\text { Estados } \\
\text { Unidos }\end{array}$ & 26/09/2002 \\
\hline 6 & $\begin{array}{lrr}\text { ACUERDO POR } & \text { NOTAS } \\
\text { REVERSALES } & \\
\text { CONCERNIENTES } & \text { A LOS } \\
\text { EJERCICIOS } & \text { MILITARES } \\
\text { CONJUNTOS PROGRAMADOS } \\
\text { PARA EL ANO 2003 CON LA } \\
\text { PARTICIPACIÓN } \\
\text { EFECTIVOS DE LAS FUERZAS } \\
\text { ARMADAS DE LOS ESTADOS } \\
\text { UNIDOS DE AMÉRICA ENTRE } \\
\text { EL GOBIERNO DE r LA } \\
\text { REPÚBLICA DEL PARAGUAY } \\
\text { Y EL GOBIERNO DE LOS } \\
\text { ESTADOS UNIDOS } \\
\text { AMÉRICA DE }\end{array}$ & Bilateral & $\begin{array}{l}\text { Acordo de } \\
\text { Exercício e } \\
\text { Intercâmbi } \\
\text { o Militar }\end{array}$ & $\begin{array}{l}\text { Estados } \\
\text { Unidos }\end{array}$ & 26/03/2003 \\
\hline
\end{tabular}




\begin{tabular}{|c|c|c|c|c|c|}
\hline 7 & \begin{tabular}{lrr} 
ACUERDO POR EL & CUAL SE \\
ESTABLECE & EL & CONSEJO \\
BILATERAL & \multicolumn{4}{r}{ SOBRE } \\
COMERCIO E INVERSIONES \\
ENTRE EL GOBIERNO DE LOS \\
ESTADOS & UNIDOS & DE \\
AMERICA Y EL GOBIERNO DE \\
LA REPUBLICA \\
PARAGUAY
\end{tabular} & Bilateral & $\begin{array}{l}\text { Investimen } \\
\text { tos }\end{array}$ & & $26 / 09 / 2003$ \\
\hline 8 & $\begin{array}{l}\text { ENMIENDA A LA CARTA } \\
\text { CONVENIO SOBRE CONTROL } \\
\text { DE DROGAS Y APLICACIÓN } \\
\text { DE LAS NORMAS LEGALES } \\
\text { ENTRE EL GOBIERNO DE LA } \\
\text { REPÚBLICA DEL PARAGUAY } \\
\text { Y EL GOBIERNO DE } \\
\text { ESTADOS } \\
\text { AMÉRICA }\end{array}$ & Bilateral & $\begin{array}{l}\text { Emenda à } \\
\text { carta } \\
\text { convênio } \\
\text { sobre } \\
\text { controle de } \\
\text { narcóticos }\end{array}$ & $\begin{array}{l}\text { Estados } \\
\text { Unidos }\end{array}$ & $26 / 09 / 2003$ \\
\hline 9 & $\begin{array}{l}\text { MEMORÁNDUM } \\
\text { ENTENDIMIENTO }\end{array}$ & Bilateral & $\begin{array}{l}\text { Propriedad } \\
\text { e } \\
\text { Intelectual }\end{array}$ & $\begin{array}{l}\text { Estados } \\
\text { Unidos }\end{array}$ & $19 / 12 / 2003$ \\
\hline
\end{tabular}




\begin{tabular}{|c|c|c|c|c|c|}
\hline 10 & $\begin{array}{llr}\text { ACUERDO } & \text { POR } & \text { NOTAS } \\
\text { REVERSALES SOBRE } & \text { LA } \\
\text { REALIZACIÓN DE EJERCICIOS } \\
\text { MILITARES CONJUNTOS CON } \\
\text { LA PARTICIPACIÓN } & \text { DE } \\
\text { MIEMBROS DE LA } & \text { FUERZAS } \\
\text { ARMADAS DE LOS ESTADOS } \\
\text { UNIDOS DE AMÉRICA ENTRE } \\
\text { EL GOBIERNO DE } \\
\text { REPÚBLICA DE PARAGUAY Y } \\
\text { EL GOBIERNO DE LOS } \\
\text { ESTADOS UNIDOS } \\
\text { AMÉRICA.NR/N } .3 / 2003\end{array}$ & Bilateral & $\begin{array}{l}\text { Acordo de } \\
\text { Exercício e } \\
\text { Intercâmbi } \\
\text { o Militar }\end{array}$ & $\begin{array}{l}\text { Estados } \\
\text { Unidos }\end{array}$ & $24 / 12 / 2003$ \\
\hline 11 & $\begin{array}{l}\text { MEMORÁNDUM } \\
\text { ENTENDIMIENTO SOBRE LOS } \\
\text { DERECHOS DE PROPIEDAD } \\
\text { INTELECTUAL ENTRE EL } \\
\text { GOBIERNO DE LOS ESTADOS } \\
\text { UNIDOS DE AMÉRICA Y EL } \\
\text { GOBIERNO DE LA REPÚBLICA } \\
\text { DEL PARAGUAY }\end{array}$ & Bilateral & $\begin{array}{l}\text { Propriedad } \\
\text { e } \\
\text { Intelectual }\end{array}$ & $\begin{array}{l}\text { Estados } \\
\text { Unidos }\end{array}$ & $30 / 03 / 2004$ \\
\hline 12 & $\begin{array}{lrr}\text { ACUERDO } & \text { POR } & \text { NOTAS } \\
\text { REVERSALES } & \text { SOBRE } & \text { UNA } \\
\text { LISTA } & \text { PARCIAL } & \text { DE } \\
\text { SEMINARIOS, CONFERENCIAS } \\
\text { E INTERCAMBIOS } \\
\text { BILATILITARES } \\
\text { MULTILATERALES } & \text { A } \\
\text { REALIZARSE } & \text { EN } & \text { EL } \\
\text { PARAGUAY DEL } & 10 / 07 / 2004 \\
\text { HASTA JUNIO DE } & \text { 2005 CON LA } \\
\text { PARTICIPACIÓN } & \text { DE } & \text { LAS } \\
\text { FUERZAS ARMADAS DE } & \text { LOS } \\
\text { ESTADOS } & \text { UNIDOS } & \text { DE } \\
\text { AMÉRICA } & \text { ENTRE } & \text { LA } \\
\text { REPÚBLICA } & \text { DEL PARAGUAY } \\
\text { Y LOS ESTADOS } & \text { UNIDOS DE } \\
\text { AMÉRICA. }\end{array}$ & Bilateral & $\begin{array}{l}\text { Acordo de } \\
\text { Exercício e } \\
\text { Intercâmbi } \\
\text { o Militar }\end{array}$ & $\begin{array}{l}\text { Estados } \\
\text { Unidos }\end{array}$ & $18 / 06 / 2004$ \\
\hline
\end{tabular}




\begin{tabular}{|c|c|c|c|c|c|}
\hline 13 & $\begin{array}{lrr}\text { CARTA CONVENIO SOBRE } \\
\text { CONTROL DE DROGAS Y } \\
\text { APLICACION DE LAS NORMAS } \\
\text { LEGALES } \text { ENTRE } \\
\text { GOBIERNO DE LA REPÚBLICA } \\
\text { DEL PARAGUAY Y Y EL } \\
\text { GOBIERNO DE LOS ESTADOS } \\
\text { UNIDOS DE AMÉRICA. }\end{array}$ & Bilateral & $\begin{array}{l}\text { Emenda à } \\
\text { carta } \\
\text { convênio } \\
\text { sobre } \\
\text { controle de } \\
\text { narcóticos }\end{array}$ & \begin{tabular}{|l} 
Estados \\
Unidos
\end{tabular} & $07 / 09 / 2004$ \\
\hline 14 & 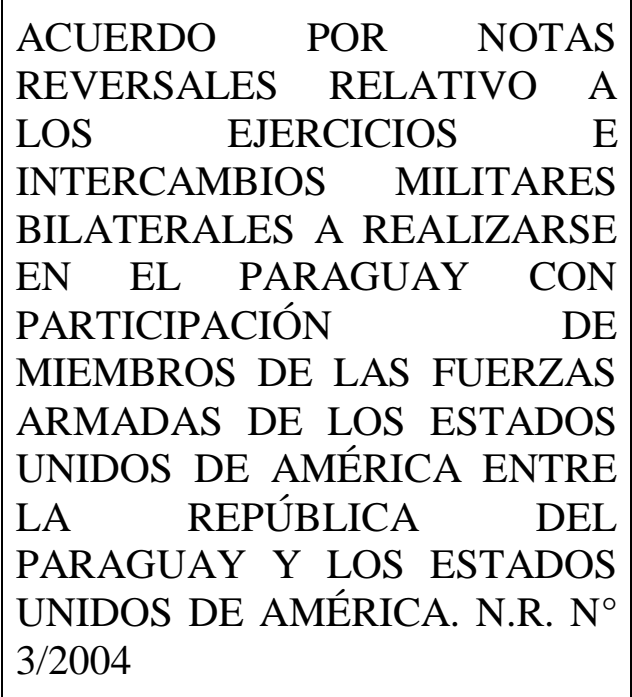 & Bilateral & $\begin{array}{l}\text { Acordo de } \\
\text { Exercício e } \\
\text { Intercâmbi } \\
\text { o Militar }\end{array}$ & \begin{tabular}{|l} 
Estados \\
Unidos
\end{tabular} & $24 / 11 / 2004$ \\
\hline 15 & $\begin{array}{l}\text { ACUERDO POR INTERCAMBIO } \\
\text { POR NOTAS REVERSALES } \\
\text { RELATIVO A LOS EJERCICIOS } \\
\text { E INTERCAMBIO MILITARES } \\
\text { BILATERALES DURANTE EL } \\
\text { PERIODO 01 DE JUNIO DE } 2005 \\
\text { AL } 31 \text { DE DICIEMBRE DE } 2006 \\
\text { ENTRE EL GOBIERNO DE LA } \\
\text { REPÚBLICA DEL PARAGUAY } \\
\text { Y EL GOBIERNO DE LOS } \\
\text { ESTADOS UNIDOS } \\
\text { AMÉRICA.N.R.N }{ }^{\circ} .2 / 2005 .\end{array}$ & Bilateral & $\begin{array}{l}\text { Acordo de } \\
\text { Exercício e } \\
\text { Intercâmbi } \\
\text { o Militar }\end{array}$ & $\begin{array}{l}\text { Estados } \\
\text { Unidos }\end{array}$ & $31 / 03 / 2005$ \\
\hline
\end{tabular}




\begin{tabular}{|c|c|c|c|c|c|}
\hline 16 & 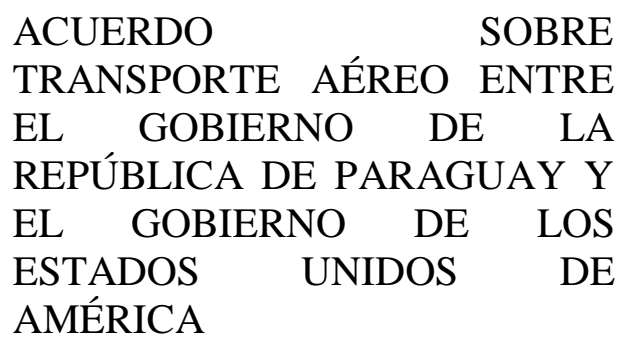 & Bilateral & $\begin{array}{l}\text { Transporte } \\
\text { Aéreo }\end{array}$ & $\begin{array}{l}\text { Estados } \\
\text { Unidos }\end{array}$ & $02 / 05 / 2005$ \\
\hline 17 & $\begin{array}{l}\text { ENMIENDA PRIMERA A LA } \\
\text { CARTA CONVENIO SOBRE } \\
\text { CONTROL DE DROGAS Y } \\
\text { APLICACIÓN DE LAS NORMAS } \\
\text { LEGALES INTRE } \\
\text { GOBIERNO DE LA REPÚBLICA } \\
\text { DEL PARAGUAY Y EL } \\
\text { GOBIERNO DE LOS ESTADOS } \\
\text { UNIDOS DE AMÉRICA }\end{array}$ & Bilateral & $\begin{array}{l}\text { Emenda à } \\
\text { carta } \\
\text { convênio } \\
\text { sobre } \\
\text { controle de } \\
\text { narcóticos }\end{array}$ & $\begin{array}{l}\text { Estados } \\
\text { Unidos }\end{array}$ & $27 / 09 / 2005$ \\
\hline 18 & $\begin{array}{l}\text { ACUERDO RELATIVO AL } \\
\text { FUNCIONAMIENTO DE UNA } \\
\text { ESTACIÓN DE VIGILANCIA } \\
\text { SÍSMICA ENTRE EL GOBIERNO } \\
\text { DE LA REPÚBLICA DEL } \\
\text { PARAGUAY Y EL GOBIERNO } \\
\text { DE LOS ESTADOS UNIDOS DE } \\
\text { AMÉRICA }\end{array}$ & Bilateral & $\begin{array}{l}\text { Acordo de } \\
\text { funcionam } \\
\text { ento de } \\
\text { uma } \\
\text { estação de } \\
\text { vigilância } \\
\text { sismica }\end{array}$ & $\begin{array}{l}\text { Estados } \\
\text { Unidos }\end{array}$ & $20 / 04 / 2006$ \\
\hline 19 & $\begin{array}{l}\text { CONVENIO DE DONACIÓN DE } \\
\text { OBJETIVO } \text { ESTRATÉGICO } \\
\text { PROGRAMA UMBRAL PARA } \\
\text { LA CUENTA DE DESAFÍO DEL } \\
\text { MILENIO } \text { ENTRE EL } \\
\text { GOBIERNO DE LA REPÚBLICA } \\
\text { DEL PARAGUAY Y EL } \\
\text { GOBIERNO DE LOS ESTADOS } \\
\text { UNIDOS DE AMÉRICA }\end{array}$ & Bilateral & $\begin{array}{l}\text { Convênio } \\
\text { para } \\
\text { redução da } \\
\text { corrupção } \\
\text { e } \\
\text { impunidad } \\
\text { e }\end{array}$ & $\begin{array}{l}\text { Estados } \\
\text { Unidos }\end{array}$ & 08/05/2006 \\
\hline
\end{tabular}




\begin{tabular}{|c|c|c|c|c|c|}
\hline 20 & $\begin{array}{l}\text { ACUERDO PARA } \\
\text { ESTABLECIMIENTO DE UN } \\
\text { FONDO DE CONSERVACIÓN } \\
\text { DE BOSQUES TROPICALES Y } \\
\text { DE UN CONSEJO DE BOSQUES } \\
\text { TROPICALES ENTRE EL } \\
\text { GOBIERNO DE LA REPÚBLICA } \\
\text { DEL PARAGUAY Y EL } \\
\text { GOBIERNO DE LOS ESTADOS } \\
\text { UNIDOS DE AMERICA }\end{array}$ & Bilateral & $\begin{array}{l}\text { Acordo } \\
\text { para o } \\
\text { estabeleci } \\
\text { mento de } \\
\text { um fundo } \\
\text { de } \\
\text { conservaçã } \\
\text { o de } \\
\text { bosques } \\
\text { tropicais }\end{array}$ & $\begin{array}{l}\text { Estados } \\
\text { Unidos }\end{array}$ & $07 / 06 / 2006$ \\
\hline 21 & 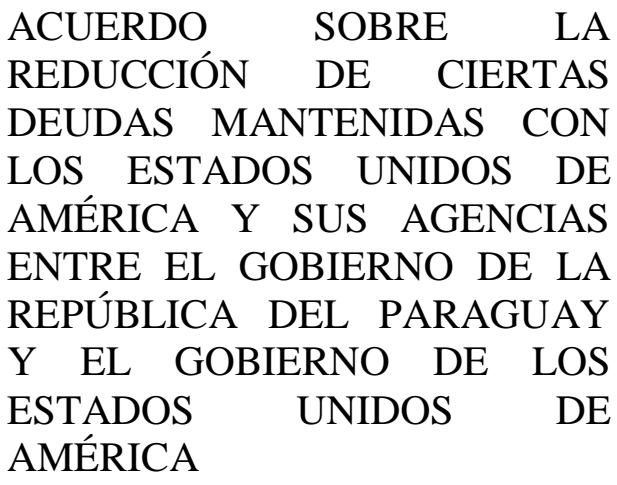 & Bilateral & $\begin{array}{l}\text { Acordo de } \\
\text { redução de } \\
\text { dividas }\end{array}$ & $\begin{array}{l}\text { Estados } \\
\text { Unidos }\end{array}$ & 07/06/2006 \\
\hline 22 & $\begin{array}{l}\text { ENMIENDA SEGUNDA A LA } \\
\text { CARTA CONVENIO ENTRE EL } \\
\text { GOBIERNO DE LA REPÚBLICA } \\
\text { DEL PARAGUAY Y EL } \\
\text { GOBIERNO DE LOS ESTADOS } \\
\text { UNIDOS DE AMÉRICA }\end{array}$ & Bilateral & $\begin{array}{l}\text { Emenda à } \\
\text { carta } \\
\text { convênio } \\
\text { sobre } \\
\text { controle de } \\
\text { narcóticos }\end{array}$ & $\begin{array}{l}\text { Estados } \\
\text { Unidos }\end{array}$ & 28/09/2006 \\
\hline 23 & $\begin{array}{llr}\text { ACUERDO } & \text { POR } & \text { NOTAS } \\
\text { REVERSALES } & \text { RELATIVO AL } \\
\text { PAGO DE LAS UTILIDADES } \\
\text { PROVENIENTES DE LA VENTA } \\
\text { DE ARTÍCULOS DE DEFENSA } \\
\text { DONADOS POR LOS ESTADOS } \\
\text { UNIDOS DE AMÉRICA ENTRE } \\
\text { EL GOBIERNO DE } \\
\text { REPÚBLICA DEL PARAGUAY } \\
\text { Y EL GOBIERNO DE LOS } \\
\text { ESTADOS } \\
\text { AMÉRICA UNIDOS }\end{array}$ & Bilateral & $\begin{array}{l}\text { Cooperaçã } \\
\text { o em } \\
\text { matéria de } \\
\text { Defesa }\end{array}$ & $\begin{array}{l}\text { Estados } \\
\text { Unidos }\end{array}$ & $14 / 04 / 2007$ \\
\hline
\end{tabular}




\begin{tabular}{|c|c|c|c|c|c|}
\hline 24 & $\begin{array}{l}\text { ENMIENDA TERCERA A LA } \\
\text { CARTA CONVENIO ENTRE EL } \\
\text { GOBIERNO DE LA REPÚBLICA } \\
\text { DEL PARAGUAY Y EL } \\
\text { GOBIERNO DE LOS ESTADOS } \\
\text { UNIDOS DE AMÉRICA }\end{array}$ & Bilateral & $\begin{array}{l}\text { Emenda à } \\
\text { carta } \\
\text { convênio } \\
\text { sobre } \\
\text { controle de } \\
\text { narcóticos }\end{array}$ & $\begin{array}{l}\text { Estados } \\
\text { Unidos }\end{array}$ & 28/09/2007 \\
\hline 25 & $\begin{array}{l}\text { MEMORÁNDUM } \\
\text { ENTENDIMIENTO SOBRE LOS } \\
\text { DERECHOS DE PROPIEDAD } \\
\text { INTELECTUAL ENTRE EL } \\
\text { GOBIERNO DE LA REPÚBLICA } \\
\text { DEL PARAGUAY Y EL } \\
\text { GOBIERNO DE LOS ESTADOS } \\
\text { UNIDOS DE AMÉRICA }\end{array}$ & Bilateral & $\begin{array}{l}\text { Propriedad } \\
\text { e } \\
\text { Intelectual }\end{array}$ & $\begin{array}{l}\text { Estados } \\
\text { Unidos }\end{array}$ & $30 / 04 / 2008$ \\
\hline 26 & $\begin{array}{l}\text { ENMIENDA CUARTA A LA } \\
\text { CARTA CONVENIO ENTRE EL } \\
\text { GOBIERNO DE LA REPÚBLICA } \\
\text { DEL PARAGUAY Y EL } \\
\text { GOBIERNO DE LOS ESTADOS } \\
\text { UNIDOS DE AMÉRICA }\end{array}$ & Bilateral & $\begin{array}{l}\text { Emenda à } \\
\text { carta } \\
\text { convênio } \\
\text { sobre } \\
\text { controle de } \\
\text { narcóticos }\end{array}$ & $\begin{array}{l}\text { Estados } \\
\text { Unidos }\end{array}$ & $15 / 07 / 2008$ \\
\hline 27 & $\begin{array}{l}\text { ENMIENDA QUINTA DE LA } \\
\text { CARTA CONVENIO ENTRE EL } \\
\text { GOBIERNO DE LA REPÚBLICA } \\
\text { DEL PARAGUAY Y EL } \\
\text { GOBIERNO DE LOS ESTADOS } \\
\text { UNIDOS DE AMÉRICA }\end{array}$ & Bilateral & $\begin{array}{l}\text { Emenda à } \\
\text { carta } \\
\text { convênio } \\
\text { sobre } \\
\text { controle de } \\
\text { narcóticos }\end{array}$ & $\begin{array}{l}\text { Estados } \\
\text { Unidos }\end{array}$ & $30 / 09 / 2008$ \\
\hline 28 & $\begin{array}{l}\text { PROGRAMA UMBRAL II PARA } \\
\text { LA CUENTA DESAFIO DEL } \\
\text { MILENIO ENTRE } \\
\text { GOBIERNO DE LA REPÚBLICA } \\
\text { DEL PARAGUAY Y EL } \\
\text { GOBIERNO DE LOS ESTADOS } \\
\text { UNIDOS DE AMÉRICA PARA } \\
\text { REDUCIR LA CORRUPCIÓN Y } \\
\text { LA IMPUNIDAD }\end{array}$ & Bilateral & $\begin{array}{l}\text { Convênio } \\
\text { para } \\
\text { redução da } \\
\text { corrupção } \\
\text { e } \\
\text { impunidad } \\
\text { e }\end{array}$ & $\begin{array}{l}\text { Estados } \\
\text { Unidos }\end{array}$ & $13 / 04 / 2009$ \\
\hline
\end{tabular}




\begin{tabular}{|c|c|c|c|c|c|}
\hline 29 & \begin{tabular}{l} 
ENMIENDA SEXTA A LA \\
CARTA CONVENIO ENTRE EL \\
GOBIERNO DE LA REPÚBLICA \\
DEL PARAGUAY Y EL \\
GOBIERNO DE LOS ESTADOS \\
\multicolumn{4}{l}{ UNIDOS DE AMÉRICA }
\end{tabular} & Bilateral & $\begin{array}{l}\text { Emenda à } \\
\text { carta } \\
\text { convênio } \\
\text { sobre } \\
\text { controle de } \\
\text { narcóticos }\end{array}$ & $\begin{array}{l}\text { Estados } \\
\text { Unidos }\end{array}$ & 28/09/2009 \\
\hline 30 & $\begin{array}{l}\text { ENMIENDA SÉPTIMA A LA } \\
\text { CARTA CONVENIO ENTRE EL } \\
\text { GOBIERNO DE LA REPÚBLICA } \\
\text { DEL PARAGUAY Y Y EL } \\
\text { GOBIERNO DE LOS ESTADOS } \\
\text { UNIDOS DE AMÉRICA }\end{array}$ & Bilateral & $\begin{array}{l}\text { Emenda à } \\
\text { carta } \\
\text { convênio } \\
\text { sobre } \\
\text { controle de } \\
\text { narcóticos }\end{array}$ & $\begin{array}{l}\text { Estados } \\
\text { Unidos }\end{array}$ & $21 / 09 / 2010$ \\
\hline 31 & $\begin{array}{l}\text { ENMIENDA OCTAVA DE LA } \\
\text { CARTA CONVENIO ENTRE EL } \\
\text { GOBIERNO DE LA REPÚBLICA } \\
\text { DEL PARAGUAY Y } \quad \text { EL } \\
\text { GOBIERNO DE LOS ESTADOS } \\
\text { UNIDOS DE AMÉRICA }\end{array}$ & Bilateral & $\begin{array}{l}\text { Emenda à } \\
\text { carta } \\
\text { convênio } \\
\text { sobre } \\
\text { controle de } \\
\text { narcóticos }\end{array}$ & $\begin{array}{l}\text { Estados } \\
\text { Unidos }\end{array}$ & $14 / 09 / 2011$ \\
\hline 32 & \begin{tabular}{l} 
ENMIENDA NOVENA DE LA \\
CARTA CONVENIO ENTRE EL \\
GOBIERNO DE LA REPÚBLICA \\
DEL PARAGUAY Y Y EL \\
GOBIERNO DE LOS ESTADOS \\
\multicolumn{4}{l}{ UNIDOS DE AMÉRICA }
\end{tabular} & Bilateral & $\begin{array}{l}\text { Emenda à } \\
\text { carta } \\
\text { convênio } \\
\text { sobre } \\
\text { controle de } \\
\text { narcóticos }\end{array}$ & $\begin{array}{l}\text { Estados } \\
\text { Unidos }\end{array}$ & $23 / 09 / 2011$ \\
\hline 33 & \begin{tabular}{l} 
ENMIENDA DIEZ A LA CARTA \\
CONVENIO ENTRE EL \\
GOBIERNO DE LA REPÚBLICA \\
DEL PARAGUAY Y $\quad$ EL \\
GOBIERNO DE LOS ESTADOS \\
\multicolumn{4}{l}{ UNIDOS DE AMÉRICA }
\end{tabular} & Bilateral & $\begin{array}{l}\text { Emenda à } \\
\text { carta } \\
\text { convênio } \\
\text { sobre } \\
\text { controle de } \\
\text { narcóticos }\end{array}$ & $\begin{array}{l}\text { Estados } \\
\text { Unidos }\end{array}$ & $19 / 09 / 2012$ \\
\hline
\end{tabular}




\begin{tabular}{|c|c|c|c|c|c|}
\hline 34 & $\begin{array}{l}\text { ENMIENDA ONCE A LA } \\
\text { CARTA CONVENIO ENTRE EL } \\
\text { GOBIERNO DE LA REPÚBLICA } \\
\text { DEL PARAGUAY Y EL } \\
\text { GOBIERNO DE LOS ESTADOS } \\
\text { UNIDOS DE AMÉRICA }\end{array}$ & Bilateral & $\begin{array}{l}\text { Emenda à } \\
\text { carta } \\
\text { convênio } \\
\text { sobre } \\
\text { controle de } \\
\text { narcóticos }\end{array}$ & $\begin{array}{l}\text { Estados } \\
\text { Unidos }\end{array}$ & 25/09/2012 \\
\hline 35 & $\begin{array}{l}\text { ENMIENDA TRECE A LA } \\
\text { CARTA CONVENIO SOBRE } \\
\text { CONTROL DE NARCÓTICOS } \\
\text { ENTRE LA REPÚBLICA DEL } \\
\text { PARAGUAY Y EL GOBIERNO } \\
\text { DE LOS ESTADOS UNIDOS DE } \\
\text { AMÉRICA }\end{array}$ & Bilateral & $\begin{array}{l}\text { Emenda à } \\
\text { carta } \\
\text { convênio } \\
\text { sobre } \\
\text { controle de } \\
\text { narcóticos }\end{array}$ & $\begin{array}{l}\text { Estados } \\
\text { Unidos }\end{array}$ & $31 / 03 / 2014$ \\
\hline 36 & $\begin{array}{l}\text { ENMIENDA DOCE A LA } \\
\text { CARTA CONVENIO SOBRE EL } \\
\text { CONTROL DE NARCÓTICOS } \\
\text { ENTRE LA REPÚBLICA DEL } \\
\text { PARAGUAY Y EL GOBIERNO } \\
\text { DE LOS ESTADOS UNIDOS DE } \\
\text { AMÉRICA }\end{array}$ & Bilateral & $\begin{array}{l}\text { Emenda à } \\
\text { carta } \\
\text { convênio } \\
\text { sobre } \\
\text { controle de } \\
\text { narcóticos }\end{array}$ & $\begin{array}{l}\text { Estados } \\
\text { Unidos }\end{array}$ & $31 / 03 / 2014$ \\
\hline
\end{tabular}

FONTE: http://www.mre.gov.py/tratados/public_web/Tratados.aspx

É observável pela tabela acima posta, que a partir de 2008, ano que coincide com a criação da UNASUL e também com o primeiro ano do mandato do Presidente Fernando Lugo, os acordos de teor especificamente militar tiveram expressiva queda em sua ocorrência, embora se tenha mantido o ritmo das relações no que toca ao controle de narcóticos. Há de se considerar alguns fatores: Primeiramente, o fato de a posse de Lugo ter significado uma guinada à esquerda, em situação similar a dos outros governos latino-americanos - como de Lula no Brasil, o casal Kirchner na Argentina, Chávez na Venezuela, Morales na Bolívia, dentre outros que sucederam ao governo durante o desenrolar de seu mandato, como o caso de Mujica que assume o governo uruguaio em 2010. A aproximação política e ideológica, por si, permitia a suposição do estabelecimento de relações mais solidárias entre os Países da vizinhança.

Historicamente, no Paraguai, assim como no Brasil, a adoção de preceitos neoliberais levou à desestruturação da economia e autonomia nacionais. O Partido Colorado, que antes sustentava a ditadura de Stroessner, se manteve no poder, juntamente às oligarquias políticas e econômicas da época ditatorial, o que, por sua vez, acabou por encaminhar o país à assimilação do neoliberalismo .XX

$\mathrm{O}$ autor continua

Cadernos do Tempo Presente, n. 24, jun./jul. 2016, p. 67-93|http://www.seer.ufs.br/index.php/tempo 


\begin{abstract}
Contudo, no bojo das bases sociais ocorreu uma reorganização dos movimentos populares e sindicais que mobilizados, sobretudo pelas Comunidades Esclesiais de Base, diminuíram progressivamente a amplitude da hegemonia do Partido Colorado e forjaram o terreno político para vitória eleitoral de Lugo, que nunca havia atuado na política partidária XXI $^{x}$
\end{abstract}

Nesse sentido, a ascensão política de Fernando Lugo, "um bispo, da Igreja Católica, Missionário do Verbo Divino e fortemente identificado com a Teologia da Libertação, [...] liderando uma heterogênea Alianza Patriótica para el Cambio (ABC) e apoiado por dezenas de organizações políticas e sociais" XXII, representa, efetivamente, uma guinada política à esquerda, que por algum tempo, deu feição mais positiva às dinâmicas regionais e, às relações bilaterais mantidas pelo Paraguai na região.

Uma manifestação que pode ser dada de exemplo naquele sentido foi a crítica paraguaia, durante Cúpula das Américas, ao bloqueio feito pelos Estados Unidos à Cuba.

O Brasil, particularmente, declarava-se como grande interessado na parceria com o Paraguai. Até o ano de 2012, segundo o Itamaraty, o Brasil era "o segundo país com maior estoque de Investimento Estrangeiro Direto (IED) no Paraguai, tendo alcançado US\$ 809 milhões". (Disponível em: www.mre.gov.br/relaçõesbilaterais). Um indício de avanço das relações entre o Brasil e o Paraguai foi o pedido brasileiro de autorização para observar, por meio de drones, o território paraguaio, em busca de focos de tráfico de drogas e outras atividades ilegais. Tal iniciativa se consolidou, mais tarde, em acordo visando justamente o controle conjunto de regiões fronteiriças. Os diálogos sobre regimes de tributação unificados e de acordos firmados entre a Petrobrás e a Petropar, a fim de legislar sobre aluguel de tanques para depósito de combustíveis fósseis, também denotava significativo avanço. Houve também conversações no sentido de se assinar Acordo Aduaneiro e na área de Segurança.

Obviamente, todos estes avanços se deram no bojo do complicado contexto das polêmicas acerca de Itaipu, mormente no que toca à concessão de energia, aos pagamentos e às cotas a serem divididas. Neste sentido, o MERCOSUL foi facilitador das relações, oferecendo crédito para construção de uma linha de transmissão de energia. Aliás, no âmbito daquele foram discutidas as assinaturas de diversos novos Acordos de complementação econômica e de livre trânsito de mercadorias. Com a entrada efetiva do Paraguai, em 2012, os debates sobre solução conjunta da crise econômica, bem como de respostas coletivas às questões de combate ao crime, Segurança e Defesa também foram fluidos, quanto aos últimos, previu-se o aprofundamento da cooperação militar, no âmbito do futuro CDS. As relações regionais seguiam, portanto, uma dinâmica contínua que não deixava de tropeçar em antigas questões regionais. Além do antigo problema de Itaipu, outro deles permanecia sério obstáculo às negociações: o protecionismo tarifário. Lugo chegou a fazer duras críticas ao Brasil e à Argentina, quando da realização da Cúpula Iberoamericana de Chefes de Estado e Governo, tanto no referente aos seus modelos econômicos, quanto à falta de solidariedade para com os Estados menos favorecidos.

Não obstante tais divergências, as relações entre Paraguai e Brasil se desenvolveram de modo muito mais amigável do que antes da gestão de Lugo. Tudo isto, de certo modo, confirmou as perspectivas de especialistas, a exemplo de Artur Bernardes de Amaral, de que, além de adotar uma postura nacional assertiva, Lugo priorizaria as relações com o Brasil. Amaral ressalvou, todavia, que Lugo tentaria estabelecer uma agenda positiva também com a 
Bolívia e com o Uruguai, na tentativa de resgatar o Urupabol, - projeto de coordenação econômica trilateral nascido em 1963. ${ }^{\text {XXIII. }}$.

Pelo acima posto, é possível compreender que o afrouxamento dos laços militares do Paraguai com os Estados Unidos tenha se relacionado ao fato de a região ter representado ao Paraguai, do governo Lugo, alguma expectativa de estabelecer vínculos mais eficazes - ainda que sua entrada efetiva na UNASUL só tenha se dado em 2012. E, ao mesmo tempo em que a região poderia representar um contrapeso às suas relações assimétricas com os Estados Unidos, sua desvantagem, dentro dela, poderia ser minimizada através da construção do eixo horizontal constituído pelo Urupabol, contrabalançando o poder do Brasil e da Argentina, por exemplo. ${ }^{\text {XIV }}$. Assim sendo, parecia haver de fato, uma estratégia paraguaia para a região.

As relações com os Estados Unidos pareciam pautadas mais pela possibilidade de cessão de benefícios, do que por qualquer aliança preferencial. Ou seja, adotavam um perfil mais instrumental, podendo ser freada no momento de qualquer desagrado diplomático. Isso pode explicar as idas e vindas das relações entre Paraguai e Estados Unidos naquele contexto.

No início do mês de novembro de 2010, Lugo recebeu visita do Subsecretário Norteamericano para Assuntos Hemisféricos, Arturo Valenzuela para debater cooperação nas áreas de segurança pública, controle ao "narcotráfico" e cooperação humanitária, conforme noticiaram os jornais ABC Color, La Nación e IP Paraguay (ABC Color - Política 08/11/2010; ABC Color - Política - 09/11/2010; La Nación - Política - 09/11/2010; IP Paraguay - Nacionales - 08/11/2010). Porém, uma crise diplomática foi desencadeada pela publicação, por meio do site Wikileaks, de documentos que indicavam que o Paraguai estava sendo espionado pelos Estados Unidos, tanto no que tocava a informações pessoais sobre candidatos à Presidência do País, quanto na presença de petróleo no Chaco. Subsequente ao pedido da chancelaria paraguaia, a Casa Branca reconheceu a oficialidade de todos os documentos divulgados pelo site Wilileaks, o que fez o Paraguai propor à Cúpula Iberoamericana a inclusão do tema para discussão. (ABC Color - Política - 30/11/2010; ABC Color - Política - 02/12/2010; IPParaguay - Miscelânias - 29/11/2010; IPParaguay Nacionales - 29/11/2010; La Nación - Política - 30/11/2010; IP Paraguay - Nacionales 01/12/2010; La Nacion - Política - 02/12/2010).

O ocorrido continuou ecoando no ano de 2011: Durante visita oficial a Quito, Lugo comentou sobre as revelações de espionagem do Departamento de Estado dos Estados Unidos, divulgadas pelo site Wikileaks, opinando que a diplomacia estadunidense teria caído a um nível muito baixo. (ABC Color - Política - 19/04/2011; La Nación - Política 19/04/2011).

No entanto, as relações diplomáticas parecem ter sido retomadas após a visita do então Embaixador dos Estados Unidos, James Harold Thessin, ao Ministro das Relações Exteriores do Paraguai, Jorge Lara Castro. Na ocasião, o primeiro declarou o interesse dos Estados Unidos no apoio ao fortalecimento da democracia, das instituições e da economia paraguaia (ABC Color - Política - 12/10/2011). Posterior a isto, o Paraguai solicitou aos Estados Unidos, a renovação de sua credencial junto ao Sistema Geral de Preferências (SGP), o qual lhe garantiria benefícios tarifários. (ABC Color - Política - 15/10/2011).

Ao passo em que o Paraguai conseguia manter o recebimento de préstimos econômicos e maiores facilidades comerciais, cresciam as cessões relacionadas ao campo estratégico e de flexibilização de sua soberania nacional, ou seja, as parcerias militares voltam a acontecer, ainda que, num primeiro momento, fossem reduzidas às ações humanitárias. No dia 31 de maio, o então vice-ministro das Relações Exteriores, Juan Esteban Aguirre, recebeu o embaixador dos EUA, James Thessin. Foram tratados temas bilaterais e jornadas cívico-

Cadernos do Tempo Presente, n. 24, jun./jul. 2016, p. 67-93| http://www.seer.ufs.br/index.php/tempo 
humanitárias, denominadas Operación Ñerpohano 17, a serem realizadas na região de Horqueta conjuntamente às Forças Militares. A operação previa a distribuição de medicamentos, provisões médicas e insumos logísticos (ABC Color - Política - 01/06/2012). Ainda que reduzidas a questões humanitárias, foi aberta uma fenda que os Estados Unidos procurariam voltar a preencher. A queda de Fernando Lugo propiciou terreno fértil para tais investidas.

Após a queda de Lugo, ficou nítido o fortalecimento das relações do Paraguai com os Estados Unidos, assim como o retrocesso nas relações do Paraguai com os países da América do Sul. Foram muitos os rumores sobre suposto apoio dos Estados Unidos à destituição de Lugo, dado à influência que vinham singelamente perdendo devido ao posicionamento político-ideológico do mandatário.

Brasil, Argentina, Uruguai, Bolívia, Venezuela, Equador, Cuba, Peru, Repúblicana Dominicana, El Salvador, Nicarágua e Panamá rechaçaram o modo como a deposição ocorreu. No seio de uma crise político-institucional e, no contexto de um confronto entre policiais e camponeses durante uma reintegração de posse de área rural, que deixou grande número de feridos, um deputado do Partido Colorado solicitou o impeachment de Lugo. A Câmara dos Senadores aprovou a destituição por 39 votos contra 4. Ao todo, o processo durou 24 horas e, embora considerado legítimo pelo Tribunal Superior Eleitoral paraguaio, não foi legitimado pela Comissão Interamericana de Direitos Humanos, principalmente pelo curto tempo para defesa que teve o acusado. A UNASUL denunciou o não cumprimento pelo Paraguai dos artigos 1, 5 e 6 do Protocolo Adicional do seu Tratado Constitutivo, referente às questões democráticas.

O vice-presidente, Frederico Franco, assumiu o novo governo, não reconhecido pela Venezuela, pelo Equador, pela Bolívia e por Cuba. No âmbito do MERCOSUL, passou-se a pensar nas possíveis sanções ao Paraguai por ferir a Cláusula Democrática. A decisão final foi a suspensão do País da Cúpula de Presidentes do bloco. Enquanto isto, Estados Unidos, Canadá, Alemanha, Espanha e Vaticano reconheciam o novo governo.

De início, a UNASUL limitou-se a apoiar o presidente destituído, Fernando Lugo, não reconhecendo seu sucessor, suspendendo, em seguida, a participação paraguaia no Conselho de Chefes de Estado do bloco. O então chanceler paraguaio, José Fernandez Estigarribia, reclamou que tal decisão feria a soberania do país.

As decisões foram repulsadas pela chancelaria paraguaia, que recorreu a diversas instâncias, como o Tribunal Permanente de Revisão do Mercosul, além de denunciar à OEA suposta perseguição que estaria sendo realizada também pela ação da ALBA, da ALADI e da CELAC. Além de não concordar com as sanções, o governo de Franco, como retaliação, decidiu aumentar o valor da energia vendida à Argentina e ao Brasil, além de ameaçar romper a cessão da mesma ao último. Isso, somado à ameaça da chancelaria Paraguai de retirar o apoio da candidatura do Brasil ao assento permanente brasileiro ao CS da ONU, fez com parlamentares brasileiros iniciassem apelo ao Executivo para que o Executivo reconsiderasse apoiar o governo do novo Presidente paraguaio. Por último, durante discurso na $67^{\mathrm{a}}$ Assembleia da ONU, em 27 de setembro de 2012, o presidente paraguaio culpou os países integrantes do MERCOSUL e da UNASUL pelas dificuldades internacionais que o País enfrentou. $O$ sentimento de lesão a sua soberania parece ter despertado no Paraguai reminiscências da rivalidade e do sentimento de injustiça que historicamente nutriu em relação a com seus vizinhos. Ao mesmo tempo em que usava de modo cada vez mais nítido, de sua relação com os Estados Unidos para fazer pressão sobre os mesmos. 


\section{A POLÍTICA EXTERNA DO PARAGUAI E A VIGÊNCIA ATUAL DE SUAS PRINCIPAIS CONDICIONANTES HISTÓRICAS. UM BALANÇO DE LUGO A CARTES}

ÉRICA C. A. WINAND

Em meio aos debates quanto à normalização democrática do Paraguai, recrudesciam as polêmicas quanto à instalação da base estadunidense no País. Pouco tempo depois de Franco assumir o governo, o presidente da Comissão de Defesa da Câmara dos Deputados, deputado José López Chávez, revelou que havia mantido conversas com generais dos Estados Unidos relativas à negociação da instalação de uma base militar no Chaco. Segundo o referido deputado que não pertencia à base aliada de Franco, tratava-se de uma operação necessária frente à corrida armamentista que estava sendo empreendida pela Bolívia. (Estadão Internacional -02/07/2012). Em 2005, a autorização feita pelo então Presidente Nicanor Duarte Frutos, para presença e livre trânsito de 500 marines estadunidenses, já havia gerado repercussões negativas entre os Países sul-americanos e gerava a suspeita quanto à futura instalação da base. O Paraguai justificava que a presença dos marines se relacionava à execução de operações humanitárias. Tanto a imprensa quanto o parlamento bolivianos mostraram notório desconforto, sobretudo em relação à suposta região de instalação: a região do Chaco já fora palco de conflito armado entre Paraguai e Bolívia entre 1932 e 1935.

No dia 14 de agosto, a ministra da Defesa do Paraguai, Maria Liz Garcia, respondeu às acusações bolivianas, negando a intenção do governo em permitir a instalação da base (ABC Color - Politica - 15/08/2012). Embora os Estados Unidos estivessem reiterando seus propósitos de boa vontade para com o Paraguai, oferecendo apoio econômico e político em repetidas situações, como durante cerimônia destinada às delegações participantes da Assembleia Geral da Organização das Nações Unidas - ONU - (ABC Color - Política 26/09/2012; La Nación - Política - 26/09/2012) e em reunião ocorrida entre o então chanceler paraguaio José Félix Estigarribia e a secretária assistente do Departamento de Estado para Assuntos Latino-Americanos dos EUA, Roberta Jackobso (ABC Color - Política 28/09/2012; La Nación - Titulares de Tapa - 28/09/2012), Franco reiterou sua não aderência à instalação da base militar, durante apresentação do Livro Branco de Defesa paraguaio.

$\mathrm{Na}$ ocasião, entretanto, o presidente Franco também ressaltou que não permitiria a intromissão de países vizinhos na tomada de decisões relacionadas a assuntos de Estado. (La Nación - Política - 04/10/2012).

Ou seja, embora tenha se aberto mais aos Estados Unidos, fato que esteve também relacionado à presença daqueles no apoio à recuperação da normalidade democrática e na organização e fiscalização das novas eleições presidenciais, Franco mostrou que tal abertura não era irrestrita. Em outro flanco, deve se ressaltar também que o não atendimento aos anseios estadunidenses de instalação da base, naquele momento, tampouco esteve relacionado a alguma tentativa de estabelecer relações menos conflitivas com o MERCOSUL e com a UNASUL, uma vez que o Presidente Franco não apenas mostrou rechaço quantos às sanções daqueles concertos contra a irrupção da ordem democrática no Paraguai, como afirmou que não aceitaria nenhum tipo de ingerência advinda daqueles.

Muito se especulou quanto à participação e ao incentivo dos Estados Unidos no ocorrido, tanto por seu interesse no retorno paraguaio às medidas liberalizantes, como na desconfiguração da coesão da UNASUL. O próprio questionamento paraguaio quanto à entrada da Venezuela e quanto à legitimidade de sua condição democrática - a julgar pelo mesmo critério que o excluiu do bloco - foram vistos como possibilidade de influência estadunidense sobre alguns grupos da elite política paraguaia. Todavia, o que nos cabe afirmar é que quanto mais a crise diplomática entre o Paraguai e seus países se agravava, mais ele se aproximava não apenas dos Estados Unidos, como de outro aliado estadunidense, a Colômbia. Ou seja, enquanto as relações com o eixo vertical permaneciam configuradas pelos diálogos com os Estados Unidos, a estratégia de contrapeso regional de Franco, através do eixo Cadernos do Tempo Presente, n. 24, jun./jul. 2016, p. 67-93|http://www.seer.ufs.br/index.php/tempo 
horizontal, reconfigurou-se, a partir do desvio do alinhamento Urupabol para o eixo ParaguaiColômbia, o que, por sua vez, abria novas frentes de insatisfação com a Argentina e, sobretudo, com a Venezuela.

Enfim, sendo ou não estimulada pelos Estados Unidos, a deposição de Lugo deflagrou grave crise diplomática na América do Sul, causando uma estagnação das negociações via MERCOSUL e via UNASUL que, naquele momento, desviaram sua preocupação e seus esforços para debater o descumprimento paraguaio das normas referentes à manutenção do Estado democrático na região. Tanto a chancelaria brasileira, como a dos outros Países da UNASUL - da maioria deles - mostraram-se intransigentes em defender que a normalização democrática só aconteceria com novas eleições, o que, por sua vez, interromperia as sanções feitas pelos concertos regionais. Franco, todavia, respondeu com o desinteresse pelo reingresso no MERCOSUL, enquanto a Venezuela fosse aceita por aquele. (ABC Color o Política - 03/05/2013).

A influência dos Estados Unidos na formulação da agenda de política exterior do Paraguai causou ainda maior impacto nas relações daquele com a América do Sul, após a eleição de Cartes que aconteceu em 21 de Abril de 2013, embora sua posse definitiva só acontecesse em 15 de agosto daquele ano.

Embora as eleições pudessem significar o retorno da ordem democrática cobrado pelos vizinhos paraguaios, e de isto representar, por sua vez, certa distensão das relações regionais, o retorno do Partido Colorado ao poder sinalizava, por um lado, o recuo a um alinhamento acrítico aos Estados Unidos, assim como o reavivar de querelas regionais relacionadas a rivalidades do passado. Antes de sua posse os narrados indícios já se mostraram claros. No dia 03 de junho, enquanto o ainda presidente Frederico Franco declarava a descoberta de petróleo na região do Chaco, em quantidade suficiente para suprir as demandas estadunidenses providas pela Venezuela e pelo Oriente Médio, uma delegação do Fundo Monetário Internacional (FMI) se reunia com Horácio Cartes, o presidente eleito, no sentido de firmar compromissos de manutenção do bom relacionamento entre a Organização e o País. (ABC Color - Política - 04/06/2013).

Por algum tempo, o Paraguai permaneceu resistente em retornar aos blocos integracionistas, dos quais fora suspenso. No caso do MERCOSUL, fora-lhe oferecida a presidência pro tempore, caso ele acatasse as decisões tomadas no período em que esteve afastado, como a entrada da Venezuela. Mas a chancelaria do País não aceitou e, ademais, informou que buscaria reparações por meio do Direito Internacional. (ABC Color - Política 14/07/2013; ABC Color - Política - 16/07/2013; IP Paraguay - Política - 11/07/2013; La Nación - Política - 12/07/2013; La Nación - Política - 16/07/2013).

Os Estados Unidos permaneceram expressando apoio às medidas políticas adotadas pelo Paraguai, além de fomentar o alinhamento do Paraguai à Aliança do Pacífico (ABC Color - Política - 24/07/2013). Por sua vez, a negociação do acordo de Complementação Econômica entre Paraguai e México, com vista à finalização de Tratado de Livre Comércio (TLC) entre ambos os países (ABC Color - Política - 22/07/2013), bem como a crescente aproximação com a Colômbia indicavam uma tendência iminente na política externa paraguaia - a saber, a opção pelo regionalismo aberto.

Em Agosto de 2013, finalmente, Horacio Cartes tomou posse que foi acompanhada pelo anúncio da chancelaria peruana, naquele momento no exercício da presidência da UNASUL, da revogação da suspensão do Paraguai do bloco (IP Paraguay - Política 10/08/2013; ABC Color - Políotica 09/08/2013; ABC Color - Política - 11/08/2013; La Nación - Política - 12/08/2013). Tal anúncio simbolizou a normalização das relações

Cadernos do Tempo Presente, n. 24, jun./jul. 2016, p. 67-93| http://www.seer.ufs.br/index.php/tempo 
paraguaias no âmbito do bloco, bem como se enquadrou no processo, já em voga, de reaproximação com seu entorno. À título ilustrativo, citamos a visita da presidente brasileira, Dilma Rousseff ao seu homólogo recém empossado, Horácio Cartes, sendo que um dos tópicos da agenda debatida fora o retorno paraguaio ao MERCOSUL (ABC Color - Política 15/08/2013; La Nación - Política - 15/08/2013).

Considerados em conjunto, os movimentos da política externa paraguaia no período demonstram que um novo viés da política externa paraguaia emerge da eleição de Cartes. A opção pelo regionalismo aberto foi expressa pelo chanceler paraguaio, Eladio Loizaga, em declaração quanto à flexibilização da decisão 32/00 que implica a participação de todos os membros quando das negociações comerciais com outros blocos. De acordo com o Chanceler, o objetivo paraguaio é permitir a abertura a outros mercados e blocos (ABC Color - Política 23/08/2013).

\section{Considerações Finais}

Consideramos, portanto, que a dependência estrutural do Paraguai aos Estados Unidos ainda é uma condicionante importante, no que toca, sobretudo, à opção das elites políticas paraguaias quanto ao modelo de desenvolvimento interno e sua relação com o modelo de projeção externa. Por seu turno, os Estados Unidos continuam buscando nos Estados mais frágeis política e economicamente, espaços de fixação de sua influência e plataformas de expansão para seu entorno imediato. Influenciar o Paraguai significa, para os Estados Unidos, ponta de lança para frear a autonomia de toda a América do Sul.

Em outra mão, o Paraguai segue dependente dos Estados mais fortes da América do Sul. Sua geografia e sua condição econômica ainda são determinantes do seu exíguo poder de barganha e, de fato, é questionável, até que ponto os vizinhos investem em melhorias de suas condições de negociação e interlocução dentro dos concertos existentes - MERCOSUL e UNASUL - para que os mesmos se tornassem, de fato, o eixo horizontal de relação do País em questão. Ao contrário, seja pelas rivalidades históricas que ainda ecoam nos intermináveis conflitos energéticos, seja pela conjuntura que destaca um líder paraguaio com pouca disposição em construir uma agenda comum com a América do Sul, o Paraguai segue não se reconhecendo como pertencente à região. Apesar de reconhecer a necessidade de se relacionar com ela, para não se isolar demasiadamente, parece continuar desconfiando que a união regional seja a melhor opção de inserção internacional, continuando a usar tanto das relações com os Estados Unidos, como de novos eixos, como a Aliança com o Pacífico, para angariar maior capacidade de interlocução.

\section{Referências Bibliográficas}

AMARAL, Artur Bernardes de. O Paraguai em 7 pontos. Revista Eletrônica Tempo Presente. Rio de Janeiro, Ano 3, №18, 2008.

CERVO, Amado. Política exterior e relações internacionais do Brasil: enfoque paradigmático. Revista Brasileira de Política Internacional. 46 (2): 5-25, 2003. 
BRICEÑO-RUIZ, José. O regionalismo latino-americano depois do regionalismo aberto: novos eixos, novas estratégias, modelos diversos. In: CARMO, et al. Relações Internacionais: Olhares Cruzados. Brasilia: Funag, 2013.

ESPÓSITO NETO, Tomaz. Os eixos da Política Externa do Paraguai de 1954 a 1989. Boletim Meridiano 47, Vol 13, No 134, 2012.

FOLETTO, Rafael. De bispo a presidente: construções histórico-midiáticas do presidente paraguaio Fernando Lugo nas revistas semanais brasileiras. Estudos em Comunicação, n.10, 2011, pp.237-254.

GUIMARÃES, Samuel Pinheiro. Estados Unidos, Venezuela e Paraguai. Carta Maior, 12/07/2012. Disponível em: http://cartamaior.com.br/?/Editoria/Internacional/EstadosUnidos-Venezuela-e-Paraguai. Acesso em dezembro de 2014.

ROLÓN, José Aparecido. Paraguai. Transição democrática e política externa. Tese de Doutorado. São Paulo: USP, 2010.

VIGEVANI, Túlio; RAMANZINI Jr, Haroldo. Autonomia, integração regional e política externa brasileira. Revista de Ciências Sociais, n2, vol.57, Rio de Janeiro, 2014.

\section{Notas}

\footnotetext{
I Doutora em História e Cultura Política pela UNESP. Professora do Departamento de Relações Internacionais da Universidade Federal de Sergipe (UFS). Membro do Grupo de Estudos de Defesa e Segurança Internacionais (GEDES). Líder do Grupo de Estudos Comparados em Política Externa e Defesa (COPEDE). Coordenadora do Informe Paraguai, no âmbito do projeto "Observatório de Política Exterior”. Secretária-Executiva da Associação Brasileira de Estudos de Defesa (ABED).

II Graduando em Relações Internacionais pela Universidade Federal de Sergipe. Bolsista PIBIC (COPES). Membro do Grupo de Estudos Comparados em Política Externa e Defesa (COPEDE). Supervisor de equipe do "Informe Paraguai", no âmbito do projeto "Observatório de Política Exterior".

III Bacharel em Relações Internacionais pela Universidade Federal de Sergipe. Membro do Grupo de Estudos Comparados em Política Externa e Defesa (COPEDE). Pesquisador e redator do "Informe Paraguai", no âmbito do projeto “Observatório de Política Exterior”. Foi bolsista PIBIC/COPES de 2013 a 2016.

Cadernos do Tempo Presente, n. 24, jun./jul. 2016, p. 67-93| http://www.seer.ufs.br/index.php/tempo
} 
${ }^{\text {IV }}$ Graduando em Relações Internacionais pela Universidade Federal de Sergipe. Membro do Grupo de Estudos Comparados em Política Externa e Defesa (COPEDE). Pesquisador e redator do "Informe Paraguai", no âmbito do projeto "Observatório de Política Exterior".

${ }^{\vee}$ Espósito Neto, 2012, p.14

${ }^{V I}$ Como um dos insumos do Projeto "Observatório de Política Exterior", coordenado pela Profa. Suzeley Kalil Mathias.

VII Guimarães, 2012, s/p

VIII Guimarães, 2012, s/p

Ix Guimarães, 2012, s/p

${ }^{\mathrm{x}}$ Espósito Neto, 2012, p.14

${ }^{\mathrm{XI}}$ Kfuri; Lamas, 2007, p.6

XII Rolón, 2010, p.105

XIII Moniz Bandeira, 2002, p.135

${ }^{\text {XIV }}$ Moniz Bandeira, 2002, p.136

xv CERVO, 2003, p.15

${ }^{\mathrm{XVI}}$ VIGEVANI; RAMANZINI, 2014, p.5

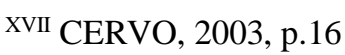

XVIII JORGE, 2009, p.80

XIX FERREIRA, 2012, p.111

xx FOLETTO, 2011, p.239

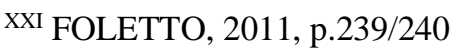

XxII FOLETTO, 2011, p.238/239

xxIII Amaral, 2008

XxIv Amaral, 2008 